\title{
Free Open Source Software in Electronics Engineering Education: A Survey
}

\author{
Vijay Nehra \\ Department of Electronics and Communication Engineering Bhagat Phool Singh Mahila Vishwavidyalaya, Khanpur- \\ Kalan, Sonipat-131305 \\ Email: nehra_vijay@yahoo.com
}

Aruna Tyagi

Department of Electronics and Communication Engineering Hindu College of Engineering, Sonipat-131001

Email:aruna007_tyagi@yahoo.co.in

\begin{abstract}
Since the last two decades, much attention has been paid to Electronics Engineering (EE) education in India. Various commercial software tools and simulator such as mathematical application packages, electronics CAD tools, learning management systems, multimedia tools and general purpose tools supports EE education. Traditionally, proprietary software packages such as OrCAD Pspice, MATLAB, LabView, Multisim and others too are widely practiced and well integrated in electronics engineering curricula of various Universities nationwide. In today's market, there are plenty of software tools and packages; however, most of them are expensive. The high cost of standard commercial packages is often hardship for students and faculties. Selecting various appropriate tools for academic use is considered as one of the key challenges in EE education. Over recent years, an alternative trend based on Free Open Source Software (FOSS) has gained momentum in higher education due to several benefits such as cost, license management flexibility, access to source code, security and stability etc. Presently, a plethora of open source software tools and resource related to EE can be deployed in teaching and learning process of EE education. In this communication, a short exposition of Free Open Source Software useful in electronics engineering education and research is presented. A brief outlook of FOSS packages, their web addresses and major highlights are also presented. The overall aim of this paper is to create awareness among instructors and students to impart active and self learning using FOSS.
\end{abstract}

Index Terms-Open Source Software, Simulation, Electronics Engineering.

\section{INTRODUCTION}

The role of software tools and simulators are well evident in engineering education and research. They also play a vital role in the development of wide variety of complex engineering system. Simulation has got a lot of applications in today's world scenario. It has found application in the area of health care, computer and communication, automobile industry, logistics and transportation system, military and scheduling etc. In the education, software tools and simulator are used for enhancing the teaching activities in various domains of electrical and electronics engineering. Generally, these software packages are available in student's version, academic purpose and commercial version, industry version [1-6]. It is well evident that popular commercial mathematical application package, MATLAB, is well integrated horizontally and vertically across various engineering disciplines and supports a wide variety of courses in specific disciplines [7-14]. Besides MATLAB, traditionally a number of commercial textual and graphical software packages such as OrCAD Pspice, Multisim, TINA, powerSim, CircuitMaker, CircuitLogix, LTSpice, Protil now knowan as Altium, logicworks, MathCAD, Mathematica, Tanner, Xilinx, VisSim, LABVIEW, HP VEE, Simulink, SystemView, EDX Signal Pro, RIDE, OPNET, STK, DASYlab support the electronics engineering education and industry $[1,3,4,6$, 15-20]. Mostly, these packages are incredibly powerful, flexible and usually well documented and supported. Some of the important points to be taken into consideration while choosing software packages are: commercial availability, cost of ownership, working platform, working capacities, scopes and output, updatability, usefulness of software, industrial acceptance, reputation of software, supports for standard and interoperability, user support, discussion form, documentation available for the version, versions and updates, integration with other software's, ease of learning and adoption, tool support, source availability, future outlook, system requirements etc. It is well known that problem solving, simulation and virtual experimentation skills can be nurtured efficiently using ICT teaching aids and software packages. Teaching learning processes supplemented by interactive Information Technology tools enhance and accelerate the learning process. Thus, the choice of appropriate free or commercial software tools is of the fundamental importance for teaching and research. The selection of various appropriate tools for academic use is considered as one of the key challenges in EE undergraduate course [21-25]. 
Beside of certain advantages, most of these commercial software packages are expensive (cost upward several lakh rupees), require annual maintenance fee for licensing and has also many drawbacks such as: lack of source code availability, dependence on the software vendor (expensive upgrades, new versions and extensions from time to time thereby increasing financial burden). Thus, along with associated high cost of software the usage of software is restricted at a specific location on the campus being licensed version. The use of specific proprietary software package also encourages illegal copying of the software. However, being costly in many cases these software packages are beyond the means of students and individuals users' academic organization. It is a cause of concern for educational and research institute in developing nations like India. The cost of a proprietary software packages is out of the reach for many technical institution and universities. Even though, it is true that students versions and some scientific packages are offered at special price to the academic institution.

Truly speaking, most of the institutions do not have sufficient resource to buy enough software package licenses for all the students. Free open source software tools have achieved a sufficient maturity and can be seriously considered as alternative to proprietary software to be used in higher education academic institution both as education and research tools. Although proprietary packages abound, there is no dearth of good free computational package too. A free operating system and a free computational package running on it help us a great deal in cutting cost. License fee and restriction on the number of users is completely irreverent. Any number of copies of the software can be installed. Resource that would otherwise be spent on procurement of costly proprietary software can be diverted to more fruitful purposes.

Since the last decade, the use of FOSS tool has gained considerable attention in science and engineering education in different fields of various disciplines across the globe. A review of electronics engineering design free software tools is presented in reference [26]. The reference [27] presents a framework for integrating free open source tools and resource as teaching resources for an electronic engineering undergraduate program for improving the learning outcomes of the students. In articles [28] free alternatives to MATLAB for undergraduate EE curricula are also discussed. In reference [29] open source software for medical images are discussed. The author of reference [30] proposes the usage of XCOS open source graphical programming environment alternative to Simulink as a teaching tool in simulation course. The author of reference [31] provided a short preview of free statistical software packages for teaching statistics to industrial technology majors.

The interested reader may refer to web site of spoken tutorial project for more detailed information about commonly used open source software tools and packages. The spoken tutorial serves as valuable self study tool [3233]. The book also serves as a better start towards the application of Scilab in electronics engineering [34]. A comparative study of open source VLSI CAD tools such as electric, magic, alliance is presented in reference [45].

Besides the above cited reference, there is a lot of literature available on FOSS tools. In nutshell, the usage of FOSS tools supports the Electronics engineering curriculum which is described in Table 1 .

In the forthcoming section, the benefit of FOSS tools for EE is described. Section 3 discusses the availability of alternatives to proprietary software which are useful for engineering education. Section 4 discusses about various e-learning management tools which are very useful in higher education. Section 5 discusses the various web addresses which are helpful in searching of design tools for engineers. Section 6 focuses on free and open source hardware tools available for engineers and section 7 concludes the need of integration of FOSS in electronics engineering education.

\section{BENEFITS FOSS TOOL}

In short, open source software is software that one can freely access, use, share, modify and redistribute the same. In recent years, the open source movement has grown. There are many decent alternatives to well known products. There are plenty of benefits and opportunities related to the open source software tools that may aid teaching and learning in EE. Computational package that are available as free/open source software are very useful for higher education and research and open and distance learning in particular. FOSS has many benefits compared with proprietary software. Some of them are as follows:

- Reduce Cost: The cost of using license is almost nothing. FOSS packages are available as free of cost or very low. It replaces a proprietary product and license fee is saved. The cost of implementation of these environments is essentially that of underlying personal computer hardware.

- Reduce Constraint: One can use FOSS package at any place any time.

- Devoting Budget to Other Academic Activities: As the usage of FOSS software in higher education results in cost saving of academic institution. Therefore, it is possible to direct greater budgetary to other academic activities such as research and development or to the improvement of the equipments of the laboratories.

- Prevention of Illegal Copying: Students can install the FOSS tool in their own computers without any restriction and thus illegal copying of software is not necessary for their academic work outside institution premises.

- Promotes Self Learning and Independent Study: Conventional laboratories were conducted using proprietary software in the traditional manner where the students were allocated into a group of two/three students and taught by a faculty member. However, 
Table 1: Structure of Electronics Engineering Curriculum

\begin{tabular}{|l|l|l|}
\hline S.No & Category & Major Subjects \\
\hline 1 & General (5-10\%) & $\begin{array}{l}\text { Desirable at least of one course in each: Communication skill, humanities, social science, } \\
\text { economics, principal of management, rural development. }\end{array}$ \\
\hline 2 & Basic Science (15-25\%) & $\begin{array}{l}\text { Minimum of one course in each of the area: Computer literacy, mathematics, physics and } \\
\text { chemistry. }\end{array}$ \\
\hline 3 & Engineering Science (10-15\%) & $\begin{array}{l}\text { Engineering graphics, workshop practices, engineering mechanics, electrical science, } \\
\text { thermodynamics and heat transfer, material science and engineering. }\end{array}$ \\
\hline Professional Subject & $\begin{array}{l}\text { Core Subjects: } \\
\text { (a) Network analysis and synthesis, signal and system, electronics device and circuits, linear } \\
\text { integrated circuits, instrumentation and control, electromagnetic theory, digital circuit and system, } \\
\text { microprocessor and microcontroller } \\
\text { (b) Telecommunication i.e. analog and digital communication, wireless communication, } \\
\text { microwave communication, antenna and wave propagation, optical communication, satellite } \\
\text { communication, digital signal processing, data communication } \\
\text { (c) Very Large Scale Integration i.e. integrated electronics \& circuits, VLSI design tools \& } \\
\text { technology, microelectronics, analog CMOS integrated circuits, system on chip design, micro } \\
\text { electro mechanical system, Very log VHDL/ embedded system etc along with basic \& engineering } \\
\text { science and humanities courses. } \\
\text { Wherever possible about 10\% elective should be made available to the students. } \\
\text { Laboratory exercise from basic and engineering science and domain course is integrated across } \\
\text { the eight semester of the program }\end{array}$ \\
\hline
\end{tabular}

using FOSS self learning and independent study may be encouraged to enhance students learning outcomes. The self-learning model significantly reduces the amount of resource required, issues of shortage of faculty, space requirement due to increase in intake and introduces flexibility in learning. Exploiting FOSS tool there is the possibility to make their homework, assignments or laboratory activities using FOSS resources.

- Access to Source Code: It provides an opportunity to study the source code by the students.

- Secure and Stable: The source code of the prototype software is open and freely available to the users who are potentials co-developers. The programmers can read, re-distribute and modify the source code for a piece of software. The users improve it, adapt it and fix bugs. In effect, distributed development calls those same people, in one or another, to participate in improving the prototype such that it becomes more sophisticated over time.

Thus, open source software can be a potential solution to ameliorate financial constraint faced by many higher education institutions and address the issues such as piracy, security and high cost. The use of open source solution offer opportunities not only to control the cost, but also expand access to the tools students need to learn as well as engage in collaborative projects. The open source movement will tap the vast pool of talents each higher education institution holds, nurturing their initiative and innovation [26-35].

Keeping in view the above benefits, it is apparent that free or open source software can be used as good alternative for engineering students.

\section{AlternAtiVE TO PROPRIETARY SOFTWARE}

There is plethora of free open source software useful for Electronics Engineering education. FOSS packages are available for mathematics, numerical analysis, parallel computing, data processing, image visualization, graphics, text preparation, and presentation and so on. The commonly used software tools are categorized as mathematical tools, circuit simulation tools, hardware design, programming and development tool, multimedia/graphics editing tool, and e-learning tool. In fact, FOSS tools may be utilized as teaching and learning aids, intuitive tool for presenting, understanding concept, mathematical modeling which is relevant to real life, thereby, stimulating student's interest in learning. In recent years, the open source movement has grown. There are many decent alternatives to well known product.

In this section, commonly used FOSS tool in basic science and professional course, general purpose tool and educational platforms used in higher education are described. The web addresses where the software can be found are given and major highlights are shown.

\section{A. Mathematical Software}

The open source initiative has also impacted mathematical application packages. In this subsection, a short preview of free software tool that may be helpful in scientific and numerical computation is presented. Table 2 lists the FOSS tools helpful in solving mathematical problems in basic science and professional course in electronics engineering. The open source packages such as Octave and Scilab are quite similar to proprietary 
package MATLAB differing mainly in degree of graphics availability and toolboxes. Octave and Scilab are free software with same level of numerical capabilities, Octave has a much closed language structured compared to one of MATLAB, Scilab is in a much more advanced developed stages with many toolbox available to the user. Besides the package as listed in Table 2, there are some sources where one can look for math's software:

- CAS. Primarily symbolic maths. http://en.wikipedia.org/wiki/comparisionof computer algebra system.

- Symbolic and numeric maths http://directory.google.com/top/science/math/algebr a/software

- Numeric maths http://en.wikipedia.org/wiki/list of numerical analysis software

- Graphics and and plotting http://en.wikipedia.org/wiki/list of graphic software Statistics softwarehttp://en.wikipedia.org/wiki/list of statistics package

\section{B. FOSS Circuit Simulation Software}

Circuit simulation play vital role in electrical and electronics engineering. A number of proprietary tools are used in circuit simulation for circuit drawing, circuit design and analysis. In this subsection, free software tools that may be helpful in analog and digital simulation, circuit simulation, schematic capture, printed circuit board (PCB) design simulation is presented. A comparative study of open source VLSI CAD tools such as electric, magic, alliance is presented in reference [45]. Table 3 lists the computer assisted open source tools helpful in electronics engineering.

\section{Electronics software}

In this section, free software tools that may be helpful in HDL design, embedded system design and microcontroller is presented. Table 4 lists the FOSS package for HDL design and embedded system design in electronics engineering.

Table 2: Some of commonly used mathematics FOSS package

\begin{tabular}{|c|c|c|c|}
\hline S .No. & Software & Web Address & Major Highlights \\
\hline 1 & Scilab & http://www.scilab.org & $\begin{array}{llll}\text { Computing environment for engineering and } & \text { scientific } \\
\text { applications. OSS alternatives to MATLAB [34-35]. } & \end{array}$ \\
\hline 2 & Octave & http://www.octave.org & $\begin{array}{l}\text { Numerical computations, OSS alternatives to MATLAB. It may } \\
\text { also be used as batch oriented language [36]. }\end{array}$ \\
\hline 3 & FreeMat & http://www.freematsourcefroge.net & $\begin{array}{l}\text { Environment for data processing and analysis similar to } \\
\text { MATLAB [37]. }\end{array}$ \\
\hline 4 & Maxima & $\begin{array}{l}\text { http://www.maxima.sourcefroge.net/downlo } \\
\text { ad.html }\end{array}$ & $\begin{array}{l}\text { Symbolic computation environment. } \\
\text { Mathematica [38]. }\end{array}$ \\
\hline 5 & Sage & http://www.sagemath.org & $\begin{array}{l}\text { Precision arithmetic, algebra, symbolic computation. Free viable } \\
\text { tool to expensive math tools such as Magma, Maple, } \\
\text { Mathematica and MATLAB [39]. }\end{array}$ \\
\hline 6 & YACAS & http://www.mathdev.sourcefroge.net & $\begin{array}{l}\text { Computer algebra system for symbolic manipulation of } \\
\text { mathematical expression [40]. }\end{array}$ \\
\hline 7 & PSPP & http://www.gnu.org/software/pspp/ & $\begin{array}{l}\text { Program for statistical analysis of sampled data. Free } \\
\text { replacement of the proprietary program SPSS [41]. }\end{array}$ \\
\hline 8 & $\mathrm{R}$ & http://www.r-project.org/ & $\begin{array}{l}\text { Language and environment for statistical computing and } \\
\text { graphics. Runs on a wide variety of platforms FreeBSD, Linux, } \\
\text { windows and MacoS [42]. }\end{array}$ \\
\hline 9 & KNIME & http://www.knime.org & $\begin{array}{l}\text { User friendly and comprehensive open source data integration, } \\
\text { processing, analysis and exploration platform [43]. }\end{array}$ \\
\hline 10 & Python & http://python.fossee.in/ & $\begin{array}{l}\text { Python supports multiple programming paradigm and used for } \\
\text { scientific computing [44]. }\end{array}$ \\
\hline
\end{tabular}


Table 3: Some of commonly used analog and digital simulation FOSS package

\begin{tabular}{|c|c|c|}
\hline S .No. & Software & Major Highlights \\
\hline \multicolumn{3}{|c|}{ Analog Simulation } \\
\hline 1 & gEDA & $\begin{array}{l}\text { Collaborative software suite used for EDA. It offers electronic design, including schematic capture, attribute } \\
\text { management, bill of materials generation, net listing, analog and digital circuit simulation, PCB layout, Verilog } \\
\text { design and GTK based waveform viewing [46]. }\end{array}$ \\
\hline 2 & Kicad & $\begin{array}{l}\text { Open source suite for electronic design automation used in design of schematic of electronic circuit, PCB } \\
\text { layout, Gerber generation. It supports all the three major platforms and features a large selection of component } \\
\text { libraries [47]. }\end{array}$ \\
\hline 3 & Ngspice & $\begin{array}{l}\text { Mixed level/mixed signal circuit simulator. Command line program based on the well known Spice-3 } \\
\text { simulator. The code is based on } 3 \text { open source software packages Spice } 3 \text { f5, Cider1b1 and Xspice. It is part of } \\
\text { gEDA project [48]. }\end{array}$ \\
\hline 4 & Xcircuit & Used to produce netlists and publish high quality drawing [49]. \\
\hline 5 & Magic & $\begin{array}{l}\text { VLSI layout design tool written by john Ousterhou in 1980's. It is Berkely open source license, run under } \\
\text { Unix Linux platforms. The newest stable version of magic is } 7.5 \text { the development version is } 8.0 \text { [50]. }\end{array}$ \\
\hline 6 & GNUCap & $\begin{array}{l}\text { GNU circuit analysis package. This Linux based circuit simulator performs various circuit analysis functions } \\
\text { such as dc and transient analysis, ac analysis etc [51]. }\end{array}$ \\
\hline 7 & KTechLab & $\begin{array}{l}\text { It is a schematic capture and simulator. It is used for mixed signal simulation of analog components and small } \\
\text { digital processor [52]. }\end{array}$ \\
\hline \multicolumn{3}{|c|}{ Digital Simulation } \\
\hline 1 & Tkgate & An event driven digital circuit simulator with a TCL/TK based graphical editor [53]. \\
\hline 2 & Logisim & An educational tool for designing and simulating digital logic circuits [54]. \\
\hline 3 & Qucas & $\begin{array}{l}\text { Quite universal circuit simulator. It can perform both analog and digital simulation. It supports schematic } \\
\text { capture, Verilog and VHDL simulation. Runs on a wide variety of platforms Solaris, Free BSD, windows and } \\
\text { Mac OS. It can simulate large signal, small signal and noise behavior [55]. }\end{array}$ \\
\hline 4 & TinyCAD & $\begin{array}{l}\text { Open source schematic capture program for MS windows. Some of feature of TinyCAD are: Drawing } \\
\text { overview, Web \& World, create PCBs and simulate with Spice. Transform diagram into PNG images [56]. }\end{array}$ \\
\hline \multicolumn{3}{|c|}{ PCB design } \\
\hline 1 & PCB & Associated with the gEDA tool suite [57]. \\
\hline 2 & FreePCB & $\begin{array}{l}\text { Easy to use and easy to learn. It has only window version. In principle, net list has to be entered semi manually } \\
\text { with a text editor [58]. }\end{array}$ \\
\hline 3 & KiCAD & Allows the user to design a printed circuit board, starting from schematic capture [59]. \\
\hline 4 & Electric & $\begin{array}{l}\text { VLSI circuit design tool with connectivity at all level. It can also be used for schematic entry and PCB design. } \\
\text { It is available under GNU GPL supports multiple OS, easy to use [60]. }\end{array}$ \\
\hline
\end{tabular}

\section{Open Source General Purpose Tool}

Open source general purpose tool supports all branches of science and engineering. Table 5 list commonly used general purpose tool.

\section{E. Common Multimedia Software}

A wide range of multimedia FOSS as indicated in Table 6 serve as a tool for enhancing educational content and its delivery. These are beneficial to create lessons and for e-learning.

\section{OPEN SOURCE E-LEARNING TOOL}

At present, there are plenty of e-learning tools available for use. Some of the Learning Management Systems (LMS) are commercial software, while other are free open source LMS. The open source LMS finds more attention for academic and education use in higher education institution. Table 7 provides a brief summary of some of the most well known FOSS e-learning management system. These educational platforms facilitate access to the material online, the remote training and allow permanent contact between teachers and students. A comparison and evaluation of open source LMS can be found in [95]. Also there is a list of Open source LMS in the link [96].

\section{FURTHER SEARCHING OF DESIGN TOOLS FOR ENGINEERS}

The important web source of information is presented in this section. Few websites that support to search for download tools are listed in Table 8.

\section{OPEN SOURCE HARDWARE}


Open source hardware (OSH) is any hardware with its design made publically available. It allows anyone to study, modify distributes, and make or sell the new design or hardware. Hardware design, including schematics, bill of materials and PCB layout data, and software that drives the hardware is released with open source approach. Ideally, OSH freely gives information:
- Users ready available components and material

- Standard process, open infrastructure

- Unrestricted content

- Open source design tools

The interested reader may refer to [102] learn more about open source hardware.

Table 4: Lists the FOSS package for HDL design and embedded system design

\begin{tabular}{|c|c|c|c|}
\hline \multicolumn{4}{|c|}{ Open Source Embedded Tool } \\
\hline S.No & Software & Web Address & Major Highlights \\
\hline 1 & NASM & http://www.nasm.us/pub/nasm/realse bulids & Assembler and disassemble for the Intel x86 architecture [61]. \\
\hline 2 & FASM & http://www.flatassembler.net/download.php & Assembler for IA-32 and x86-64 computer architectures [62] \\
\hline 3 & GNU Binutils & http://www.ftp.gnu.org/gnu/binutils/ & Assembler, compilers for micro controllers and DSP processor [63]. \\
\hline 4 & RTAI & http://www.RTAI.org & Real time operating system for desktop and embedded system [64]. \\
\hline 5 & SDCC & $\begin{array}{l}\text { http://www.sdcc.sourceforge } \\
\text { /index.php\#download }\end{array}$ & GCC SDCC complier for 8051 microcontroller [65]. \\
\hline \multicolumn{4}{|c|}{ HDL compilation, simulation and data visualization } \\
\hline 1 & Lcarus & http.gpleda.org/index.html & Command line verilog compiler associated with gEDA[66]. \\
\hline 2 & Veriwell & http://sourcefrofe.net/projects/veriwell/ & Command line verilog compiler which output VCD files[67]. \\
\hline 3 & ghdl, freehdl & http:// ghdl.free.fr/download.html & $\begin{array}{l}\text { Command line VHDL compiler that can analyze or execute a design } \\
\text { [68]. }\end{array}$ \\
\hline 4 & Signs & http://www.iti.unistuttgart.de/ bartscgr/signs/ & $\begin{array}{l}\text { Can be used either as command line or as an eclipse plug in for } \\
\text { hardware design and simulation [69]. }\end{array}$ \\
\hline 5 & Verilator & http://www.veripool.org/wiki/verilator & $\begin{array}{l}\text { It is the fastest free Verilog HDL simulator. It compiles } \\
\text { synthesizable Verilog into cycle accurate } \mathrm{C}++ \text { or system } \mathrm{C} \text { code } \\
\text { [70]. }\end{array}$ \\
\hline
\end{tabular}

Table 5: Some of commonly used General Purpose Tool FOSS

\begin{tabular}{|l|l|l|}
\hline \multicolumn{2}{|l|}{ Text Editing Tool (All branches of science and engineering) } \\
\hline S.No. & Software & Major Highlights \\
\hline 1 & $\begin{array}{l}\text { Open office } \\
\text { (word processing office } \\
\text { suite) }\end{array}$ & $\begin{array}{l}\text { This is the most widely used open source office suite. It has word processor, spreadsheet, presentation and } \\
\text { drawing program that can replace the proprietary equivalents. It is available in many languages and works } \\
\text { on all common computers and in several operative systems [71]. }\end{array}$ \\
\hline 2 & LaTex & Scientific typesetting tool [72]. \\
\hline Connectivity Tool & $\begin{array}{l}\text { Mozilla } \\
\text { (web browsing) }\end{array}$ & $\begin{array}{l}\text { Mozilla Firefox is a Web Browser like Internet Explorer, Opera, or Google Chrome. Its advantage is that it } \\
\text { is faster and more secure than Internet Explorer. }\end{array}$ \\
\hline 1 & & \\
\hline
\end{tabular}


Table 6: Some of commonly used Multimedia FOSS Tool

\begin{tabular}{|c|c|c|}
\hline \multicolumn{3}{|c|}{ Multimedia FOSS ( audio, video, graphics, general ) } \\
\hline S.No. & Software & Major Highlights \\
\hline 1 & $\begin{array}{l}\text { Audacity } \\
\text { (sound recording) }\end{array}$ & $\begin{array}{l}\text { Fast multi track audio editor and recorder. It is used for recording and editing sounds, play sounds, and } \\
\text { import and export file in various format. It can be used to edit audio, mix tracks together or apply effects } \\
\text { to your recording. It is available for Mac, Microsoft window, GNU/linux and other operating system [74]. }\end{array}$ \\
\hline 2 & Ardor & It is a digital audio workstation. It can be used to record edit, edit and mix multi track audio [75]. \\
\hline 3 & Media player & Used for playbacks of videos and other multimedia content [76]. \\
\hline 4 & VLC Player & $\begin{array}{l}\text { Free and open source cross platform multimedia player and framework that plays most multimedia files as } \\
\text { well as DVD, Audio CD and various streaming protocols [77]. }\end{array}$ \\
\hline 5 & $\begin{array}{l}\text { HandBrake } \\
\text { (DVD repping) }\end{array}$ & Open source DVD to MPEG-4 converter [78]. \\
\hline 6 & Infra Recorder & Open source CD and DVD recording package. Used to produce CD's and DVD's [79]. \\
\hline 7 & $\begin{array}{l}\text { GNU Image } \\
\text { manipulation } \\
\text { programme }\end{array}$ & Used for image editing and graphic design. FOSS equivalent of proprietary Photoshop software [80]. \\
\hline 8 & Open office draw & Free open source vector graphics application better and cheaper than Corel Draw [81]. \\
\hline 9 & Visio and smart draw & $\begin{array}{l}\text { Used for drawing of many different kinds of diagrams. It has special objects to facilitate the drawing of } \\
\text { flow charts, network diagrams and simple circuits [82]. }\end{array}$ \\
\hline 10 & Pencil & $\begin{array}{l}\text { Used to produce a wide range of animation. It enables to create traditional hand drawn animation using } \\
\text { both bit map and vector graphics [83]. }\end{array}$ \\
\hline 11 & Lightworks & Open source professional video editing tool [84]. \\
\hline 12 & $\begin{array}{l}\text { Blender } \\
\text { (3 D Graphics) }\end{array}$ & Free and open source 3D animation tool [85]. \\
\hline
\end{tabular}

Table 7: Some of commonly used Learning Management Systems

\begin{tabular}{|l|l|l|}
\hline \multicolumn{1}{|c|}{ S.No } & \multicolumn{1}{|c|}{ Software } & \multicolumn{1}{|c|}{ Major Highlights } \\
\hline 1 & $\begin{array}{l}\text { Moodle[86], Atutor[87], Dokeos[88], Dotlrn[89], } \\
\text { Sakai[90], } \\
\text { ILIAS[92],Claroline[93],OLAT[94]. }\end{array}$ & $\begin{array}{l}\text { Learning Management Systems (LMS) is a software application that helps } \\
\text { in educational, administrative and deployment requirements. It simplifies } \\
\text { the process of administering education and training. It provides an } \\
\text { instructor with tools to create and deliver online content, monitor student } \\
\text { participation and assess student's performance. } \\
\text { Sakai and Moodle are most popular platforms. }\end{array}$ \\
\hline
\end{tabular}

Table 8: Further Searching of Design Tools for Engineers

\begin{tabular}{|l|l|l|}
\hline S.No. & Web Address & Major Highlights \\
\hline 1 & $\begin{array}{l}\text { www.sourcefroge.net/directory/science- } \\
\text { engineering/os:linux/freshness: recently-updated }\end{array}$ & $\begin{array}{l}\text { Dedicated section provides information about each software, links to } \\
\text { download and the home page of all open source software that are available } \\
\text { for engineers [97]. }\end{array}$ \\
\hline 2 & http://download.cnet.com & $\begin{array}{l}\text { It is a resource for free to try or free software downloads. It also feature a } \\
\text { list of the most popular downloads reviews and rating of software, which } \\
\text { help in deciding what to download [98]. }\end{array}$ \\
\hline 3 & http://softpedia.com & $\begin{array}{l}\text { Vast collection of free and free to try software for windows, Unix, linux } \\
\text { operating system [99]. }\end{array}$ \\
\hline 4 & $\begin{array}{l}\text { http://onlineengineeringprograms.org/2011/top-25- } \\
\text { open-source-software-apps-for-engineers/ } \\
\text { fluid dynamics application and application for space engineering [100]. }\end{array}$ \\
\hline 5 & $\begin{array}{l}\text { http://wiki.developspace.ne/Open_Source_Engineerin } \\
\text { g_tools }\end{array}$ & $\begin{array}{l}\text { Enlist open source engineering tools such as space specific software, } \\
\text { computer aided design software, numerical programming languages and } \\
\text { visualization software and electronic design automation packages [101]. }\end{array}$ \\
\hline
\end{tabular}




\section{CONCLUSION}

The role of open source in electronics industry is broadening, paving a career path for enthusiast. There is an increasing demand for electronics engineers who are experienced in open source technologies, mainly due to a change in development towards a more social and collaborative development environment. The skills set required for open source electronics engineers are as follows:

- Strong understanding of hardware and its working,

- Digital electronics fundamental, system domains and operating system,

- Good understanding of computer architecture,

- Knowledge of C and assembly language,

- Problem solving and debugging skill,

- Knowledge of microprocessor and microcontroller.

There is no doubt that the teachers and teaching techniques play an important role in the process of learning. There is an urgent need to change the mode of delivery of engineering course using FOSS tools and innovative teaching approach. Modification of curriculum by horizontal and vertical integration ICT and FOSS full featured scientific software package may be used in engineering course at university level. Conventional laboratory courses such circuit simulation, digital signal processing, control system laboratory and other too are well integrated across electrical and electronics engineering curricula globally. Truly speaking, the sessions in these laboratories were conducted using proprietary software in the traditional manner where the students were allocated into a group of two/three students and taught by a faculty member. However, to promote self-learning and independent study among students self learning computer laboratory session using Free Open Source Software may be encouraged to enhance students learning outcomes. The self learning model significantly reduces the amount of resource required, issues of shortage of faculty, space requirement due to increase in intake and introduces flexibility in learning. Exploiting FOSS tool there is the possibility to make their homework, assignments or laboratory activities using FOSS resources.

Horizontal integration of LMS and ICT across the academic programme and vertical integration of FOSS along with proprietary software tools across Electronics and Communication Engineering pave the way to develop problem solving skills and a better understanding of experimental skills. The use of more than one software package across various courses in electronics engineering is not considered a problem but rather advantages, which makes future engineers eager to test and use new tools, instead of being stuck to only what they have used in past. To sum up, effective utilization of multimedia, World Wide Web, innovative teaching methods using FOSS packages in electronics engineering has the potential not only to improve the education, but also to empower the people thereby paving the way to achieve the human development goal of the state.

Learning management systems are educational platform that may be integrated horizontally and vertically across all the courses and supports the whole academic programme. Numerical computation FOSS package supports basic science courses and domain course. Analog and digital simulation tool, programming and development tool, graphic programming environment, development boards for embedded system supports the domain courses. The general purpose and multimedia tool supports basic science, engineering and administrative activities in EE programme.

\section{REFERENCES}

[1] B Chuco P, Electrical software tools overview, Online. Available at: http://www. eurostag.regimov.net/files/DOC2.pdf.

[2] Claudio A Canizares, Zeno.T Faur, "Advantages and disadvantages of using various computer tools in electrical engineering courses," IEEE Transactions on education, vol. 40, No. 3, pp 1-7, August 1997.

[3] Tsvetanka Kovacheva, Mathematical packages for teaching and research in internet-application and support, International Journal Information Theories \& Application, vol. 11, pp 387-393, 2004.

[4] Miguel Garcia, Hugo Coll, Diana Bri, Jaime Lloret, Software tools and simulators in the education of engineering of telecommunications, In the Proceedings of $5^{\text {th }}$ WSEAS/ IASME International Conference on Engineering Education, July 22-24, Heraklion, Greece, pp337-342, 2008.

[5] Mahmood Nagrial, Education and training in engineering software and applications, International Conference on Engineering Education, August 18-21, Manchester, U.K, 2002.

[6] Jaromir Antoch, Environment for statistical computing, Computer Science Review, vol. 2, No.1, pp 113-122, 2008.

[7] Alex Palamids and Anastasia Veloni, Signals and systems laboratory with MATLAB, CRC press, 2010.

[8] K C Raveendranathan, Communication systems modeling and simulation using MATLAB and Simulink, University Press, 2011.

[9] Evelyn Brown, Rick Wiliams Purvis Bedenbaugh, An example of vertical integration in an engineering curriculum, proceeding of ASEE Southeast Section Conference, University Of Memphis ,Memphis, Tennessee, April 6 - 8, pp. 56, 2008.

[10] Pan Feng, Lin Mingxiu, Xue Dingyu, Chen Dali, Cui Jianjiang, Application of MATLAB in teaching reform and cultivation of innovation talents in universities, In the Proceedings of IEEE $2^{\text {nd }}$ International Workshop on Education Technology and Computer Science, pp. 700-703, 2010.

[11] Hazim H. Tahir, Teresa Fernandez Pareja, MATLAB package and science subjects for undergraduate studies, International Journal for Cross-Disciplinary subjects in education (IJCDSE), vol. 1, no.1, pp 38-42, March 2010.

[12] Shailendra Jain, Modeling and simulation using MATLAB-Simulink, Wiley India, 2011.

[13] O I Okoro, P Govender, E Chikuni, A new user-friendly software for teaching and research in engineering education, The Pacific Journal of Science and Technology, vol. 7, no.2, pp 130-136, 2006. 
[14] J Z Zhang, K Burbank, Bridging the gap between theory and practice-an example of teaching communications courses using MATLAB, Proceeding of American Society for Engineering Education-Pacific Southwest, 2004.

[15] Cory L. Clark, LabVIEW Digital Signal Processing, McGrraw Hill, 2005.

[16] M H. Rashid, Introduction to PSpice OrCAD for circuits and electronics, Pearson, 2004.

[17] E. Lunca, S Ursache and O Neacsu, Graphical programming tools for electrical engineering higher education, International Journal of Online Engineering, vol. 7, no.1, pp. 19-24, 2011.

[18] Salahuddian Qazi and Naseem Ishaq, Use of graphical programming tools for electrical engineering and technology courses, In Proceeding of American Society for Engineering Education Annual Conference and Exposition, 2002.

[19] Nikunja K. Swain, James A. Anderson and Raghu B. Korrapati, Role of Simulation Software in Enhancing Student Learning in Computer Organization and Microcontroller Courses in proceedings International Conference IAJC-IJME, 2008.

[20] Khadije Khatiri1, Fatemeh Rabiee, The Role of Simulation Software in Learning and Reminding (Case Study on Matlab, Packet Trace, Pspice and Opnet), J. Basic. Appl. Sci. Res.,vol. 2, no.6, pp.6178-6181, 2012.

[21] Vijay Nehra and Sandeep Dahiya, Effectiveness of ICT to Enhance Problem Solving, Simulation, Experimental and Communication Skills: Experiences, Observation and Recommendation, In Proceeding of Proceedings of the $7^{\text {th }}$ National Conference; INDIACom-2013,Computing For Nation Development, Bharati Vidyapeeth's Institute of Computer Applications and Management (BVICAM), New Delhi, $7^{\text {th }}-8^{\text {th }}$ March, 2013.

[22] Vijay Nehra and Sandeep Dahiya, Role of Simulation Tool in Enhancing Teaching and Learning of Information and Communication Technology: A Case Study, In Proceedings of the $5^{\text {th }}$ National Conference; INDIACom2011Computing for Nation Development, March 10 - 11, 2011.

[23] V S Damodharan and V Rengarajan, "Innovative method of teaching", Online. Available at: http://www.math.arizona.edu/ atpmena/conference/p roceedings.

[24] Y Wang, Using student-centred teaching approaches in the course of Analog Electronic Circuit http://science.uniserve.edu.au/pubs/china/vol5/CP5_eng_0 1.pdf.

[25] Konstantinos B. Baltzis and Konstantinos D. Koukias, Using Laboratory Experiments and Circuit Simulation IT Tools in an Undergraduate Course in Analog Electronics Journal of Science Education and Technology, Vol. 18, No. 6, pp. 546-555, 2009.

[26] C medrano, I Plaza, M Castro, Garica- Sevilla, J D, Josep Pou Fleix, M Corbalan, A review of electronics engineering design free software tools, In the proceedings of IEEE EDUCON educational Engineering, Madrid, Spain, April 14-16, 2010.

[27] Gustavo Adolfo Meneses Benavides, Integrating free open source tools as teaching resources for an electronic engineering undergraduate program, Latin American and Caribbean Journal of Engineering Education, vol 5, no.2, pp 24-32,2011.

[28] Ahmad M Ibrahim, Free alternatives to MATLAB for undergraduate Electronics Engineering Curricula, Proceeding of IEEE, 2006.
[29] Ralf Dreesen, Open source software for medical images http://www.cs.uni-paderborn.de/fileadmin/Informatik/AGDomik/teaching/seminar/medical_images/openSource.pdf.

[30] Leros A. and Andreatos A., Using Xcos as a teaching tool in simulation course, In Proceedings of the $6^{\text {th }}$ International Conference on Communications and Information Technology (CIT '12), Recent Researches in Communications, Information Science and Education, World Scientific and Engineering Academy and Society (WSEAS) Stevens Point, Wisconsin, USA, March 7-9, 121-126, 2012, D.O.A: 18.12.2013.

[31] Xiaoping Zhu and Ognjen Kuljaca, A short preview of free statistical software packages for teaching statistics to industrial technology majors, Journal of Industrial Technology, vol. 21, no.2, pp 1-6, 2005.

[32] K M Moudgalya, Spoken tutorial: a collaborative and scalable educational technology, CSI Communications, vol., 35, no. 6, pp.10-11, 2011.

[33] Spoken tutorial, Available at: http://www.spokentutorial.org, D.O.A: 18.12.2013.

[34] Hema Ramachandran and Achuthsankar S. Nair, SCILAB (A free software to MATLAB), S Chand, 2012.

[35] Introduction to SCILAB. Online. Available at: http://www.scilab.org, D.O.A: 16.12.2013.

[36] Gnu Octave. Online. Available at: http://www.gnu.org/software/octave/download.html, D.O.A: 16.12 .2013 .

[37] Freemat. Online. Available at: http://www.freematsourcefroge.net, D.O.A: 16.12.2013.

[38] Maxima: A computer Algebra System. Online. Available at: http://www.maxima .sourcefroge.net/ download.html, D.O.A: 16.12 .2013 .

[39] Sage: open source mathematics software. Online. Available at: http://www.sagemath.org, D.O.A: 16.12.2013.

[40] YACAS: A free and Open source computer Algebra System. Online. Available at: http://www.mathdev.sourcefroge.net, D.O.A: 16.12.2013.

[41] PSPP: GNU Project. Online. Available at: http://www.gnu.org/software/pspp, D.O.A: 16.12.2013.

[42] The R Project for statistical computing. Online. Available at: http://www.r-project.org, D.O.A: 16.12.2013.

[43] Knime-Professional Open Source software. Online. Available at: http://www.knime.org, D.O.A: 16.12.2013.

[44] Fossee Python: Free and open source for science and Engineering education. Online. Available at: http:www.//python.fossee.in, D.O.A: 16.12.2013.

[45] VLSI CAD Tools. Online. Available at: http://www.OpenSource VLSI CAD Tools: A Comparative Study, online. Available lin.asee.org/Conference2010/Papers/A1_Liu_Anan.p df, D.O.A: 16.12.2013.

[46] GEDA: EDA tool. Online. Available at: http://www.geda.seul.org, D.O.A: 16.12.2013.

[47] Kicad: EDA software suite. Online. Available at: http://www.Kicad-pcb.org, D.O.A: 16.12.2013.

[48] Ngspice-circuit simulator. Online. Available at: http://www.ngspice.sourceforge.net/download.html, D.O.A: 16.12.2013.

[49] Xcircuit: Open circuit design. Online. Available at: http://opencircuitdesign.com/xcircuit/download.html, D.O.A: 16.12 .2013 .

[50] Magic: Open circuit design. Online. Available at: http: //www.opencircuitdesign.com/magic/download.html, D.O.A: 16.12.2013.

[51] Gnucap: circuit Analysis Package. Online. Available at: http://www.gnucap.org, D.O.A: 16.12.2013. 
[52] Ktechlab: IDE for microcontroller and Electronics. Online. Available at: http://www sourceforge.net/ projects/ktechlab, D.O.A: 16.12.2013.

[53] TKgate- Digital Circuit Simulator. Online. Available at: http://www.tkgate.org, D.O.A: 16.12.2013.

[54] Logisim: graphical tool for designing \& simulating logic circuits. Online. Available at: http://www.ozark. hendrix.edu/ burch/logisim, D.O.A: 16.12.2013.

[55] QUCS: A Universal Circuit Simulator. Online. Available at: http://qucs.sourceforge.net/index.html, D.O.A: 16.12.2013.

[56] Tinycad: Schematic Capture Program. Online. Available at: http:// tinycad.sourcefroge.net, D.O.A: 16.12.2013.

[57] GEDA: Schematic Capture Program. Online. Available at: http://www.geda.org, D.O.A: 16.12.2013.

[58] PCB Layout Editor. Online. Available at: http://www.freepcb.com, D.O.A: 16.12.2013.

[59] Kicad: An EDA software tool. Online. Available at: http://www.kicad-pcb.org, D.O.A: 16.12.2013.

[60] Electric: electric CAD System. Online. Available at: http://www.gnu.org/s/electric, D.O.A: 16.12.2013.

[61] Nasm: The Netwide Assembler. Online. Available at: http://www.nasm.us/pub/nasm/realsebulids, D.O.A: 16.12.2013.

[62] Fasm: Assembler for DOS, Windows and Linux operating System. Online. Available at: http://www.flatassembler.net/download.php, D.O.A: 18.12.2013.

[63] Binutils: A GNU Operating System. Online. Available at: http://www.ftp.gnu.org/gnu/binutils, D.O.A: 18.12.2013.

[64] RTAI: Realtime Application Interface. Online. Available at: http://www.RTAI.org, D.O.A: 18.12.2013.

[65] SDCC: Small Device C Compiler. Online. Available at: http://sdcc.sourceforge.net/index.php\#download, D.O.A: 18.12.2013.

[66] Gpleda: An EDA Tool. Online. Available at: http://www.gpleda.org/index.html, D.O.A: 18.12.2013.

[67] Veriwell: Open Source Software development Program. Online. Available

at: http://sourcefroge.net/projects/veriwell, D.O.A: 18.12.2013.

[68] Ghld: A VHDL Compiler. Online. Available at: http:// ghdl.free.fr/download.html, D.O.A: 18.12.2013.

[69] Signs: EDA Tool for VHDL Hardware Development Online. Available

at: http://www.iti.unistuttgart.de/ bartscgr/signs, D.O.A: 18.12.2013.

[70] Verilator: Verilog HDL Simulator. Online. Available at: http://www.veripool.org/wiki/verilator, D.O.A: 18.12.2013.

[71] Open Office: The Free and Open Source Productivity Suite. Online. Available at: http://www.download.openoffice.org, D.O.A: 18.12.2013.

[72] Latex: A document Preparation Tool. Online. Available at: http://www.latex-project.org/ftp.html, D.O.A: 18.12.2013.

[73] Mozilla: A free and open Source Web Browser. Online. Available at: http://www.mozilla.org, D.O.A: 18.12.2013.

[74] Audacity: Free Audio Editor and Recorder. Online. Available at: http://www.audacity.sourcefroge.net, D.O.A: 18.12.2013.

[75] Ardour: the Digital Audio Workstation. Online. Available at: http://www.ardour.org, D.O.A: 18.12.2013.

[76] Winamp: A free and Open source media Player. Online. Available at: http://www.winamp.com/media-player, D.O.A: 18.12 .2013
[77] VLC: A free and Open source media Player. Online. Available at: http://www.vlc-mediaplayer.en.softonic.com, D.O.A: 18.12.2013.

[78] Handbrake: A free and Open source video Transcoder. Online. Available at: http://www.handbrake.fr, D.O.A: 18.12.2013.

[79] Infrarecoder: free and Open source CD/DVD burning System. Online. Available at: http://www.infrarecorder.org, D.O.A: 18.12 .2013 .

[80] Gimp: The GNU Image Manipulation Program Online. Available at: http://www.gimp.org, D.O.A: 18.12.2013.

[81] OpenOffice Draw: A free and Open source Suite. Online. Available at: http://www.openoffice.org, D.O.A: 18.12.2013.

[82] SmartDraw: Automated software for Flowchart, Org Charts and Floor Plan etc. Online. Available at: http://www.smartdraw.com, D.O.A: 18.12.2013.

[83] Pencil: A traditional 2D Animation Software. Online. Available at: http://www.pencil-animation.org, D.O.A: 18.12.2013.

[84] Lightworks: A Video Editing Program. Online. Available at: http://www.lwks.com, D.O.A: 18.12.2013.

[85] Blender: A 3D Creation Suite. Online. Available at: http://www.blender.org, D.O.A: 18.12.2013.

[86] Moodle: A free and Open source Web Applicaion. Online. Available at: http://www.moodle.org, D.O.A: 18.12.2013.

[87] Atutor: A Learning Management System. Online. Available at: http://www. atutor.ca, D.O.A: 18.12.2013.

[88] Dokeos: A free and Open source E-Learning Program. Online. Available at: http:// www.dokeos.com, D.O.A: 18.12.2013.

[89] Dotlrn: A free and Open source E-Learning Program Online. Available at: http://www.dotlrn.org, D.O.A: 18.12.2013.

[90] Sakai: A free and Open source E-Learning Program Online. Available at: https://sakaiproject.org, D.O.A: 18.12.2013.

[91] Eduplone: A Content Management System. Online. Available at: http://eduplone.org, D.O.A: 18.12.2013.

[92] ILIAS:A free and Open source E-Learning Program Online. Available at: http://www.ilias.de, D.O.A: 18.12.2013.

[93] Claroline: A free and Open source E-Learning Program Online. Available at: http://www.claroline.net, D.O.A: 18.12.2013.

[94] Olat: A free and Open source E-Learning Program. Online. Available at: http://www.olat.org, D.O.A: 18.12.2013.

[95] Itmazi, J.A., Megias, M.G., Paderewski, P. and Vela, F.L.G., "A comparison and evaluations of open source learning management systems", In Proceedings of the IADIS International Conference in Applied Computing, 80-86, 2005, D.O.A: 18.12.2013.

[96] Wikipedia: List of Learning Management System. Online. Available http://www.en.wikipedia.org/wiki/List_of_learning_manag ement_systems, D.O.A: 18.12.2013.

[97] Linux: A free and Open source Operating System. Online. Available at: http://www.sourcefroge.net/directory/scienceengineering/os:linux/ freshness: recently-updated, D.O.A: 18.12.2013.

[98] Cnet: Free software download site. Online. Available at: http://download.cnet.com, D.O.A: 18.12.2013.

[99] Softpedia: A Website Monitoring Application. Online. Available at: http://softpedia.com, D.O.A: 18.12.2013.

[100] Top-25-open-source- software-apps-for-engineers. Online. 
Available at: http://onlineengineeringprograms.org /2011/top-25-open-source- software-apps-for-engineers, D.O.A: 18.12.2013.

[101] DevelopSpace: A free and Open source Engineering Tool. Online. Available at: http://wiki.developspace.ne/Open_Source_Engineering_to ols, D.O.A: 18.12.2013.

[102] Open Source Hardwares. Online. Available at: http://www.openhardware.org. D.O.A: 18.12.2013.

\section{Biographical notes:}

Vijay Nehra is currently working as Associate Professor and Chairperson, Department of Electronics and Communication Engineering, Bhagat Phool Singh Mahila Vishwavidyalaya, Khanpur, Sonepat, Haryana, India. He holds Ph.D in Electronics His research area includes signal processing, plasma electronics. He has professional experience of 12 years in teaching, research, curriculum planning, laboratory development, educational administration, planning, management and execution. His current area of interest include engineering education teaching strategies that promote professionalism and career development, learning style and innovative laboratories that crosscut the curriculum. He is a life member of various professional societies such as ISTE, CSI, IETE, Institution of Engineers, Plasma Science Society of India.

Aruna Tyagi is presently working as Assistant Professor at the Department of Electronics and Communication Engineering, Hindu College of Engineering, Sonepat, Haryana, India. She is M.Tech in Electronics and Communication Engineering and pursuing Ph.D. Her research area includes digital signal processing and brain-computer interface. Her current area of interest includes integration of new teaching strategies in engineering education. She has published research papers in various international journals and attended various international and national conferences.

How to cite this paper: Vijay Nehra, Aruna Tyagi,"Free Open Source Software in Electronics Engineering Education: A Survey", IJMECS, vol.6, no.5, pp.15-25, 2014.DOI: 10.5815/ijmecs.2014.05.03 